\title{
Low-Temperature Discotic Nematic Liquid Crystals
}
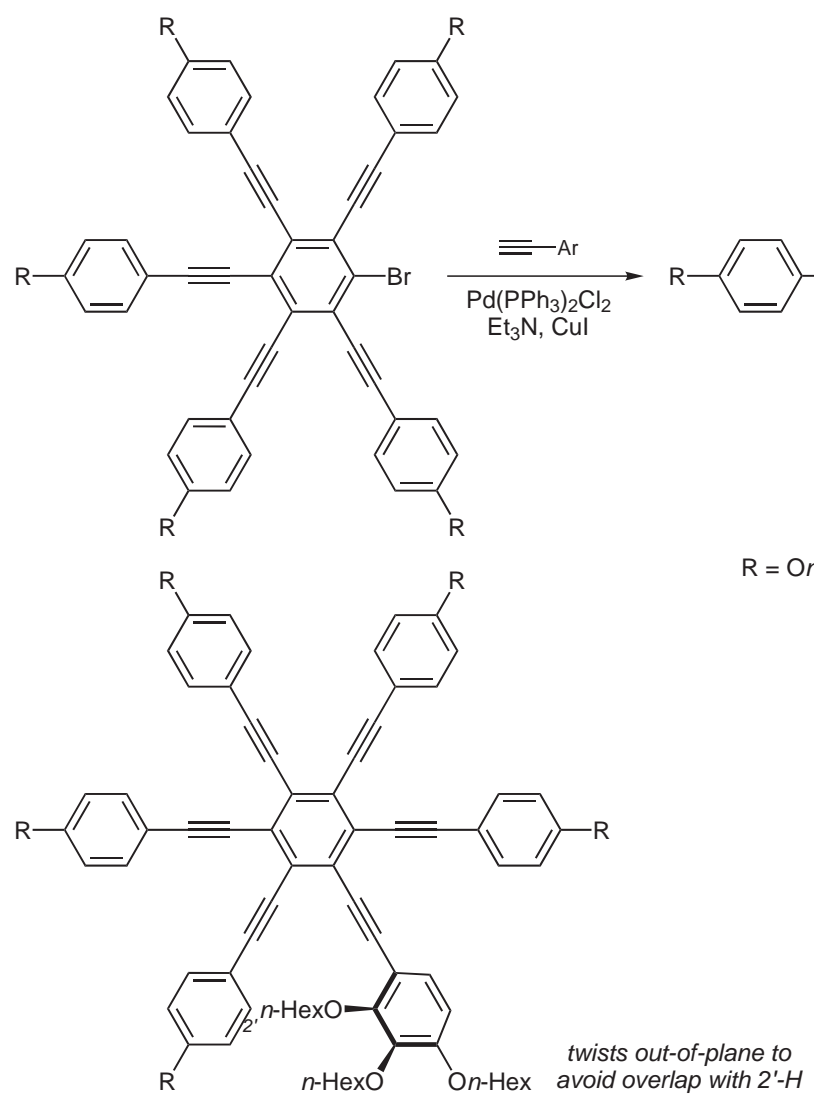

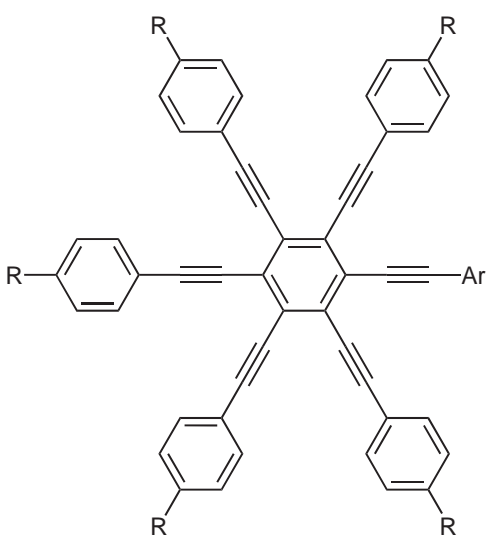

$\mathrm{R}=\mathrm{O} n$-Hex (4 examples), $\mathrm{C}_{8} \mathrm{H}_{17}$ (1 example)
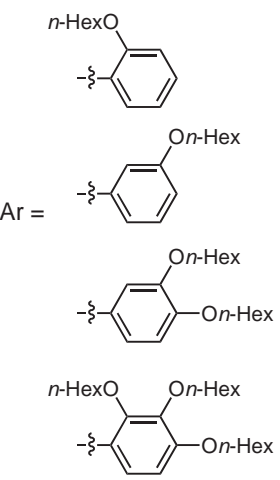

\section{Key words}

alkynylbenzenes

discotic liquid crystals

nematic liquid crystals

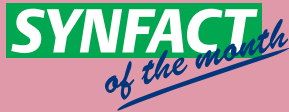

Significance: Replacement of one of the 6-symmetrical para-substituted aryl groups in the hexaalkynylbenzene moiety with an aromatic ring possessing 'lateral' (ortho and/or meta) substitution gives disklike molecules that exhibit the discotic nematic $\left(N_{D}\right)$ liquid crystal (LC) phase. The authors are able to achieve low temperature $\left(30^{\circ} \mathrm{C}\right)$ noncolumnar $\mathrm{N}_{\mathrm{D}} \mathrm{LC}$. It is likely that the large ortho substituents cause the laterally substituted aryl ring to twist out of plane. These same substituents then provide a steric barrier to column formation.
Comment: There are relatively few examples of $\mathrm{N}_{\mathrm{D}}$ liquid crystals; this is in contrast to the large number of calamitic (rod) nematic LCs, which make up the bulk of liquid crystal display (LCD) technology. By making simple but highly effective modifications to the well-established (see: Chimia 1987, 41, 196) hexaalkynylbenzene scaffold the authors have developed a variety of discotic LCs with good nematic properties. This technique is likely to find further use in the development of lowtemperature $\mathrm{N}_{\mathrm{D}}$ liquid crystals.

SYNFACTS Contributors: Timothy M. Swager, Ryan M. Moslin Dol: 10.1055/s-2007-991279; Reg-No.: S10807SF 